02

\title{
Спектроскопические свойства полимерных пленок, активированных супрамолекулярным наноалмазным комплексом европия с батофенантролином
}

\author{
(C) В.А. Лапина, Т.А. Павич, П.П. Першукевич \\ Институт физики им. Б.И. Степанова НАН Беларуси, \\ 220072 Минск, Беларусь \\ e-mail: p.persh@ifanbel.bas-net.by
}

Поступила в Редакцию 21.12.2018 г.

В окончательной редакции 21.12.2018 г.

Принята к публикации 15.03.2019 г.

\begin{abstract}
Впервые с использованием супрамолекулярного алмазсодержащего комплекса европия (III) с батофенантролином получены новые люминесцентные пленки, с высокой эффективностью преобразующие УФ излучение в диапазоне длин волн $220-410 \mathrm{~nm}$ в люминесценцию ионов европия, с возможностью регулирования степенью монохроматичности излучения в главной полосе излучения ионов $\mathrm{Eu}^{3+} \mathrm{c}$ максимумом $615 \mathrm{~nm}$. Установлено, что форма спектров возбуждения, полуширина главной полосы испускания $615 \mathrm{~nm}$ (переход $\left.{ }^{5} D_{0}-{ }^{7} F_{2}\right)$, значения квантовых выходов (в пределах $\sim 0.3-0.8$ ) зависят от типа материала матрицы. Предлагаемые оптические материалы могут найти применение при разработке различных светоизлучающих устройств: экранов, индикаторов, солнечных концентраторов, органических светодиодов, лазерных сред.
\end{abstract}

Ключевые слова: люминесцирующие полимерные пленки, алмазосодержащие комплексы европия (III), преобразование УФ излучения.

DOI: $10.21883 /$ OS.2019.08.48035.370-18

\section{Введение}

В настоящее время существует большая заинтересованность в получении полимерных и металлоорганических материалов, в частности, с использованием редкоземельных элементов (РЗЭ), для технологий фотоники и оптоэлектроники. Известно использование комплексных соединений европия (III) в виде оптически активных твердотельных матриц для лазеров [1], в качестве светотрансформирующих покрытий [2] и концентраторов энергии в солнечных элементах [3-5], в органических светодиодах $[1,6-9]$, в качестве меток для флуоресцентного иммуноанализа $[1,10]$, в люминесцентных датчиках температуры [11-13], в качестве индикаторов радиационного излучения [14]. Развитие нанотехнологий дало новый толчок для разработки перспективных материалов с использованием РЗЭ, в частности ионов европия (III), обладающих набором полезных свойств, таких как однородность, прозрачность, фотостабильность, хорошая адгезия при сохранении высокой эффективности люминесценции. Ряду исследовательских групп удалось добиться значительных успехов в разработке таких материалов [15-20], в которых в качестве матриц использовались органические [16-19] или неорганические полимеры, например органо-неорганические гибридные материалы в виде гель-стекол $[15,20]$.

В большом количестве работ при разработке новых полимерных материалов применялся двухлигандный $\beta$-дикетонатный комплекс европия (III) $\mathrm{c}$ трис(теноилтрифторацетоном) и 1,10-фенантролином $\left(\mathrm{Eu}(\mathrm{TTA})_{3}\right.$ phen $)$. Кроме $\mathrm{Eu}(\mathrm{TTA})_{3}$ phen, большой ин- терес представляет комплекс европия (III) с батофенантролином $\left(\mathrm{Eu}(\mathrm{bphen})_{2}\left(\mathrm{NO}_{3}\right)_{3}\right.$, далее $\left.\mathrm{EuB}\right)$, характеризующийся высокой интенсивностью люминесценции $[21,22]$, фото- и термостойкостью [21]. Известно также, что благодаря своим полупроволниковым свойствам $\mathrm{EuB}$ используется в светодиодных устройствах $[9,23]$.

В нашей недавней работе [24] сообщалось о возможности получения поликристаллов (порошков) супрамолекулярного комплекса европия (III) с батофенантролином $\mathrm{Eu}(\mathrm{bphen})_{2}\left(\mathrm{NO}_{3}\right)_{3}$, в котором в качестве структурообразующего элемента были использованы наноалмазы (ND, nanodiamonds) детонационного синтеза. Было показано, что полученный комплекс стабилен, способен преобразовывать излучение УФ диапазона в видимый свет, обладает эффективной люминесценцией в области $615 \mathrm{~nm}$. Поскольку для практического использования наиболее востребованными являются прозрачные материалы в твердом состоянии, целью настоящей работы явилась разработка светотрансформирущих прозрачных материалов в виде пленок, преобразующих УФ излучение в видимый свет, активированных разработанным нами супрамолекулярным алмазсодержащим комплексом европия с батофенантролином, ND-Eu(bphen $)_{2}\left(\mathrm{NO}_{3}\right)_{2}$ (далее $\mathrm{ND}-\mathrm{EuB})$, введенным в различные полимерные матрицы и гель-стекло.

\section{Образцы и методы эксперимента}

Синтез комплекса ND-EuB описан в работе [24]. Для изготовления люминесцентных пленочных композитов в 
качестве твердотельной матрицы использовались такие полимеры, как полистирол (PS), поливинилбутираль (PVB), полиметилметакрилат (РММА) и полиакрилонитрид (PAN) фирмы Aldrich. Концентрация комплекса в поливочных растворах составляла $0.1 \mathrm{wt} . \%$ в полимере. Люминесцентный композит получали путем диспергирования комплекса в 10\%-ном растворе полимера при непрерывном перемешивании на магнитной мешалке с последующим гомогенизированием в ультразвуковой ванне $(42 \mathrm{kHz})$ в течение $30 \mathrm{~min}$ при $40^{\circ} \mathrm{C}$. Полученную композицию наносили на кварцевые подложки методом полива из раствора при помощи „мажущей“ фильеры с дальнейшим высушиванием в сушильной камере в течение $24 \mathrm{~h}$ при $35^{\circ} \mathrm{C}$. Полученные таким образом люминесцентные пленки имели толщину 20-70 $\mu \mathrm{m}$.

Тонкие гель-пленки (до $20 \mu \mathrm{m}$ ), полученные золь-гель методом, были получены из раствора методом центрифугирования (spin-on films). Реакционная смесь содержала фенилтриметоксисилан (phenyltrimethoxysilane, PTMS), диметилдиэтоксисилан (dimethyldiethoxysilane, DMDES), воду, этанол в мольном соотношении PTMS:DMTES: $\mathrm{H}_{2} \mathrm{O}: \mathrm{C}_{2} \mathrm{H}_{5} \mathrm{OH}=1: 1: 5: 10$. После тщательного перемешивания смеси на магнитной мешалке в течение $6 \mathrm{~h}$ добавляли порошок ND-EuB в мольном соотношении 0.015 к золь-гель раствору и гомогенизировали в ультразвуковой $(42 \mathrm{kHz})$ ванне в течение $1 \mathrm{~h}$ при $40^{\circ} \mathrm{C}$. Для полного прохождения процесса гидролиза реакционную смесь выдерживали при комнатной температуре в течение суток. Далее пленкообразующий раствор разливался по подложке, после чего осуществлялось быстрое раскручивание до скорости $2000 \mathrm{rpm}$. Подложки с полученными пленками сушились путем медленного повышения температуры $\left(1^{\circ} \mathrm{C} / \mathrm{min}\right)$ до $120^{\circ} \mathrm{C}$ в течение $20 \mathrm{~min}$.

Измерения скорректированных спектров люминесценции (СЛ) и спектров возбуждения люминесценции (СВЛ) проводились на модернизированном спектрофлуориметрическом комплексе СДЛ-2 (ЛОМО, СССР), основанном на монохроматорах возбуждения и регистрации соответственно МДР-12 и МДР-23. В качестве источника возбуждения использовалась ксеноновая лампа ДКсШ-120. Регистрация светового сигнала после прохождения монохроматора осуществлялась с помощью охлаждаемого фотоумножителя ФЭУ-100 (диапазон 230-800 nm) в режиме счета фотонов.

Квантовые выходы прозрачных пленок оценивались относительным методом. В качестве эталона использовалась прозрачная пленка $\mathrm{Eu}(\mathrm{TTA})_{3}$ phen в PMMA $\left(\varphi_{F}=0.68\right)$. Спектры поглощения и пропускания исследуемых пленок измерялись на спектрофотометре Cary500 Scan UV-Vis-NIR (Varian, США, Австралия). Регистрация кинетики затухания свечения производилась импульсным методом с помощью цифрового осциллографа BORDO 221 (полоса пропускания $150 \mathrm{MHz}$ ). Источником возбуждения служила импульсная ксеноновая лампа (длительность импульса $\sim 2 \mu \mathrm{s}, \quad \lambda_{\text {ехс }} \sim 350 \mathrm{~nm}$, $\left.\Delta \lambda_{1 / 2} \sim 20 \mathrm{~nm}\right)$. Ввиду близости к экспоненте кривых

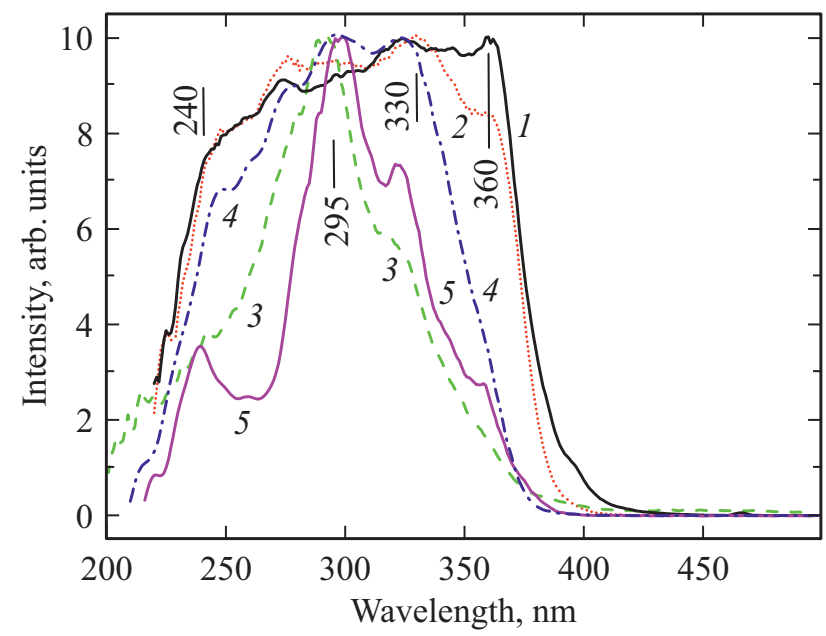

Рис. 1. Спектры возбуждения люминесценции порошков $(1,2)$ и пленок (3-5) из PMMA (3), PAN (4) и SOL-GEL (5): 1 - комплекс $\mathrm{EuB} ; 2-5$ - супрамолекулярный комплекс с наноалмазами $\mathrm{ND}-\mathrm{EuB}\left(\lambda_{\mathrm{mon}}=615 \mathrm{~nm}\right)$.

затухания люминесценции $I(t)$ средние времена затухания $\tau_{0}$ каждого из исследуемых объектов были достаточно близки к временам экспоненциального затухания $\tau_{e}$, определяемым по наклону зависимости $\ln I(t)$ от времени $t$. Исследование топографии поверхности образцов проводилось на сканирующем зондовом микроскопе $(\mathrm{C} 3 \mathrm{M})$ в составе многофункционального комплекса NanoFlex (Solar LS, Беларусь).

\section{Экспериментальные результаты и их обсуждение}

На рис. 1-4 и в таблице представлены основные результаты исследования спектрально-люминесцентных свойств полученных нами образцов. На рис. 1 сопоставлены СВЛ поликристаллов исходного комплекса $\mathrm{EuB}$ (кривая 1) и комплекса с наноалмазами ND-EuB (кривая 2), а также пленок, активированных комплексом $\mathrm{ND}-\mathrm{EuB}$, введенным в полимеры PMMA, PAN и гельстекло (далее также гель-пленки или SOL-GEL). CВЛ всех образцов получены при регистрации в максимуме полосы электродипольного перехода ${ }^{5} D_{0}-{ }^{7} F_{2}$ каждого из полимерных образцов $(615 \mathrm{~nm})$. Как видно из рис. 1 , СВЛ всех образцов представляют собой широкие структурные полосы, расположенные в УФ области (от 200 до $410 \mathrm{~nm}$ ) с главными максимумами вблизи 360, 330, 290, 295 и $298 \mathrm{~nm}$ соответственно для образцов поликристаллов с $\mathrm{EuB}$ и $\mathrm{ND}-\mathrm{EuB}$, а также пленок с внедренным комплексом ND-EuB в PMMA, PAN и SOLGEL. Видно, что степень структурности СВЛ зависит от вида матрицы. Наибольшей полушириной обладает СВЛ образца ND-EuB в PAN (кривая 4). Наибольшей степенью структурности обладает СВЛ образца ND-EuB в гель-стекле (кривая 5). 
Значения времен затухания $\tau_{0}$ и квантовых выходов $\varphi$ исследуемых объектов при $\lambda_{\text {ехс }}=350 \mathrm{~nm}$ и $\lambda_{\text {mon }}=615 \mathrm{~nm}$

\begin{tabular}{c|c|c|c|c|c|c|c}
\hline Образец & EuB & ND-EuB & ND-EuB in PS & ND-EuB in PVB & ND-EuB in PMMA & ND-EuB in PAN & ND-EuB in SOL-GEL \\
\hline$\tau_{0}, \mathrm{~ms}$ & 1.24 & 0.90 & 0.95 & 1.06 & 1.12 & 0.95 & 1.03 \\
$\varphi$ & 0.93 & 0.85 & 0.58 & 0.46 & 0.37 & 0.30 & 0.78
\end{tabular}

Примечание. Значения $\varphi$ для пленок следует рассматривать как оценочные, приблизительные.

Большинство полос возбуждения образцов ND-EuB в матрицах совпадает с полосами поликристаллического образца. К таковым относятся полосы вблизи 360, 325, 295 и $240 \mathrm{~nm}$. Однако в зависимости от вида полимера наблюдаются и существенные различия. Некоторые полосы, характерные для поликристаллических образцов, исчезают при введении ND-EuB в матрицы. Так, в спектрах СВЛ полосы в области $360 \mathrm{~nm}$ не проявляются для комплекса ND-EuB в PMMA и PAN, а в золь-гельстекле, наоборот, эта полоса отчетливо видна. В области 275 nm полосы ND-EuB в PMMA и в SOL-GEL полностью отсутствуют, а образец ND-EuB в PAN обладает такой полосой.

Следует также заметить, что СВЛ исследованных нами образцов ND-EuB в PS и PVB (на рис. 1 не показаны) смещены относительно СВЛ ND-EuB в PMMA соответственно в длинноволновую и коротковолновую области. С учетом вышесказанного диапазон возбуждения красной люминесценции ионов $\mathrm{Eu}^{3+}$ простирается от 220 до $410 \mathrm{~nm}$.

Как видно из рис. $2, a, b$, спектры люминесценции (СЛ) достаточно разнообразны и также зависят от вида матрицы. Различие между CЛ $\mathrm{EuB}$ и $\mathrm{ND}-\mathrm{EuB}$ (кривые 1 и 2) обсуждено в нашей предыдущей работе [24]. Согласно [24], это различие связано с симметрией локального кристаллического поля, действующего на ионы $\mathrm{Eu}^{3+}$. CЛ пленки ND-EuB в PMMA (кривая 3) практически совпадает со спектром поликристаллического образца ND-EuB (кривая 2). Форма спектров ND-EuB в PS и PVB (на рисунках не показана) аналогична. От спектров этой группы образцов в полимерных матрицах сильно отличается поведение спектра ND-EuB в PAN. Так, в области полос магнитно-дипольного ${ }^{5} D_{0}-{ }^{7} F_{1}$ перехода форма спектра (и особенно интенсивность) группы линий образца ND-EuB в PAN значительно отличается от аналогичных характеристик группы линий ND-EuB в PMMA (на рис. 2, $b$ кривые 3 и 4). В области полос „сверхчувствительного“ электродипольного перехода ${ }^{5} D_{0}-{ }^{7} F_{2}$ полуширина главной полосы $\Delta \lambda_{1 / 2}$ (длина волны максимума $615.1 \mathrm{~nm}) \mathrm{ND}-\mathrm{EuB}$ в PAN почти в 3 раза превосходит аналогичную величину ND-EuB в РММА. Сильные различия по форме и интенсивности спектров для обсуждаемых образцов наблюдаются и в области полос ${ }^{5} D_{0}-{ }^{7} F_{3}-,{ }^{5} D_{0}-{ }^{7} F_{4}$-переходов. Например, для образца ND-EuB в PMMA и в PAN соотношение интенсивностей на длинах волн $\sim 685$ и $\sim 700 \mathrm{~nm}$ противоположно, а относительная интенсивность всей группы полос образца ND-EuB в PMMA явно ниже аналогичной величины для образца ND-EuB в PAN (на рис. 2, $a$ кривые 3 и 4).
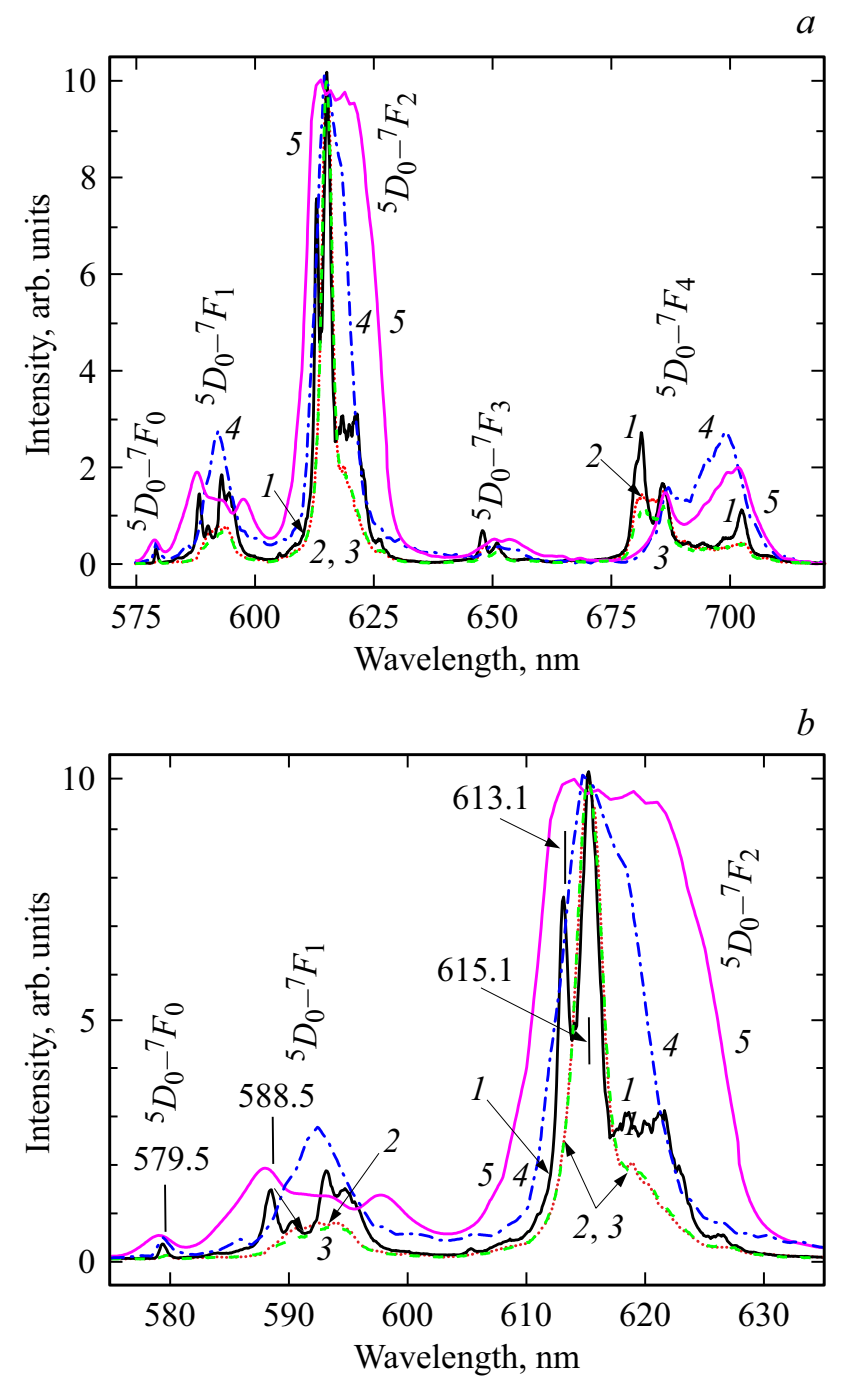

Рис. 2. Спектры люминесценции в широком $(a)$ и узком $(b)$ спектральных диапазонах порошков $(1,2)$ и пленок (3-5) из PMMA (3), PAN (4) и SOL-GEL (5): 1 - комплекс $\mathrm{EuB} ; 2-5$ - супрамолекулярный комплекс с наноалмазами $\mathrm{ND}-\mathrm{EuB}\left(\lambda_{\mathrm{exc}}=350 \mathrm{~nm}\right)$.

Среди исследованных образцов своим особенным спектром наиболее выделяется образец ND-EuB в SOL-GEL. Прежде всего это относится к полуширине главной полосы ${ }^{5} D_{0}-{ }^{7} F_{2}$-перехода (рис. 2, кривая 5). Так, полуширина этой полосы в SOL-GEL составляет $17 \mathrm{~nm}$ против 3.5 и $9 \mathrm{~nm}$ в PMМА и PAN. Кроме того, в области ${ }^{5} D_{0}-{ }^{7} F_{1}$-перехода спектр группы полос существенно отличается по сравнению с этой характери- 


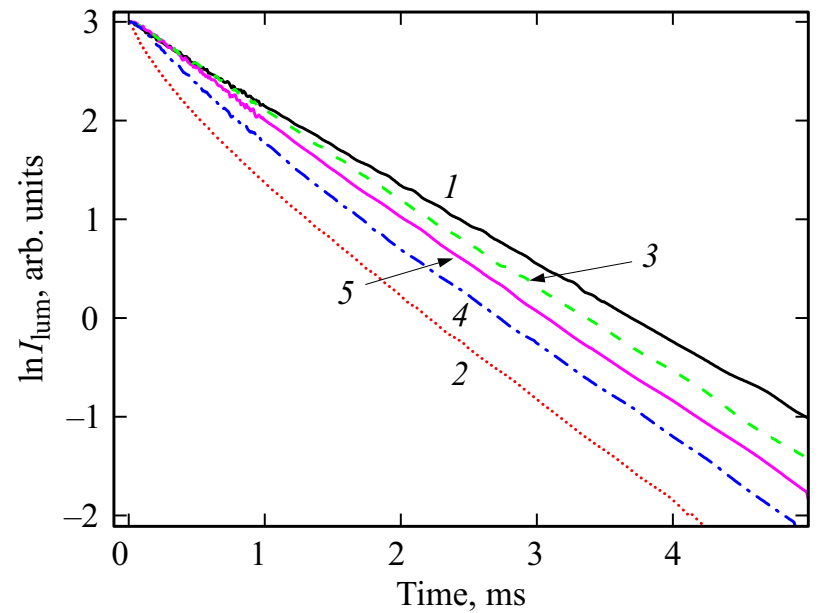

Рис. 3. Логарифмы кривых затухания люминесценции порошков $(1,2)$ и пленок (3-5) из PMМА (3), PAN (4) и SOL-GEL (5): 1 - комплекс EuB; 2-5 - супрамолекулярный комплекс с наноалмазами $\mathrm{ND}-\mathrm{EuB}$. $\left(\lambda_{\mathrm{exc}}=350 \mathrm{~nm}\right.$, $\left.\lambda_{\text {mon }}=615 \mathrm{~nm}\right)$.

стикой для всех исследуемых нами образцов. В области полос ${ }^{5} D_{0}-{ }^{7} F_{3}-$ и ${ }^{5} D_{0}-{ }^{7} F_{4}$-переходов спектр ND-EuB в SOL-GEL не совпадает ни с одним из спектров исследуемых нами образцов, однако в некоторой степени по форме и соотношению интенсивности полос подобен спектру ND-EuB в PAN. Как нам представляется, необычно большую полуширину полосы $615 \mathrm{~nm}$ в PAN (и особенно в SOL-GEL) можно объяснить более сильным взаимодействием комплекса с матрицей, например большим числом взаимодействующих групп атомов.

Результаты по измерению кинетики затухания люминесценции $I(t)$ исследуемых образцов показаны на рис. 3 и в таблице. Из представленных данных видно, что наиболее медленным затуханием $\left(\tau_{0}^{\mathrm{EuB}}=1.24 \mathrm{~ms}\right)$ характеризуется порошок ЕuB, a наиболее быстрым и неэкспоненциальным - порошок ND-EuB $\left(\tau_{0}^{\mathrm{ND}-\mathrm{EuB}}=0.90 \mathrm{~ms}\right)$. По сравнению $\mathrm{c} \mathrm{ND}-\mathrm{EuB}$ в ряду матриц PAN, SOL-GEL, PMMA происходит постепенное возрастание $\tau_{0}$. В таком же порядке снижается степень неэкспоненциальности кривых затухания. Определенные нами параметры затухания по конечной стадии затухания $\tau_{e}$ достаточно близки к средним временам затухания $\tau_{0}$, так как степень неэкспоненциальности кривых затухания достаточно мала. Например, согласно [24], при аппроксимации кривых двумя экспонентами для EuB среднее время затухания $\tau_{0}^{\mathrm{EuB}}=1.24 \mathrm{~ms}$, а $\tau_{e}^{\mathrm{EuB}}=1.27 \mathrm{~ms}$.

Оцененные нами значения квантовых выходов $\tau$ (таблица) для $\mathrm{ND}-\mathrm{EuB}$ в матрицах достаточно велики. Наибольшим значением квантового выхода характеризуется ND-EuB в SOL-GEL ( $\left.\varphi_{\mathrm{SG}}=0.78\right)$, наименьшим в PAN $\left(\varphi_{\text {PAN }}=0.30\right)$. Как следует из таблицы, значения квантовых выходов $\varphi$ не всегда располагаются в порядке возрастания $\tau_{e}$.

На рис. $4, a, b$ и $5, a, b$ представлены микрофотографии пленок для образцов, полученных в SOL-GEL и в PAN.
Для образца в SOL-GEL (рис. $4, a, b$ ) видно, что пленка достаточно однородна по геометрии и имеет шероховатость с регулярным рельефом поверхности. Из рис. $4, b$ видно, что частицы комплекса распределены в матричном материале в виде сферических частиц с размером до $1 \mu \mathrm{m}$, близко расположены к друг другу и образуют цепочечные структуры с плотной упаковкой. Такое взаимное расположение частиц определяется как химией матричного материала, так и структурой и химией поверхности самого комплекса. Поверхностный рельеф пленки просматривается в виде микро- и наноструктур, близких по форме и размерам (выступы, углубления, впадины), т.е. в виде достаточно регулярно профилированных сдвоенных столбчатых структур. Такая структура может обеспечить повышенную адгезию поверхности пленки к другим твердым поверхностям (эффект „сухой“ адгезии). При сопоставлении рис. $4, a$ и $4, b$ видно, что наблюдаются также выступы больших размеров, что свидетельствует об агрегации частиц комплексов в агломераты разной величины, вплоть до $2.5 \mu \mathrm{m}$.

Топография поверхности для PAN-пленки (рис. 5, $a, b$ ) выглядит по другому. Пленка имеет отличную от SOLGEL топографию поверхности: распределение частиц в пленке не так однородно, размер частиц в целом значительно меньше, в среднем латеральный размер частиц составляет $0.2 \mu \mathrm{m}$, видно образование агрегатов в среднем до $0.6 \mu \mathrm{m}$, форма частиц не имеет такой четко выраженной сферической формы, как на рис. $4, a$, частицы не образуют цепочечных структур, а расположены достаточно хаотично. Поверхностный рельеф пленки просматривается в основном в виде небольших впадин и углублений и имеет наноразмерный характер. Выступы

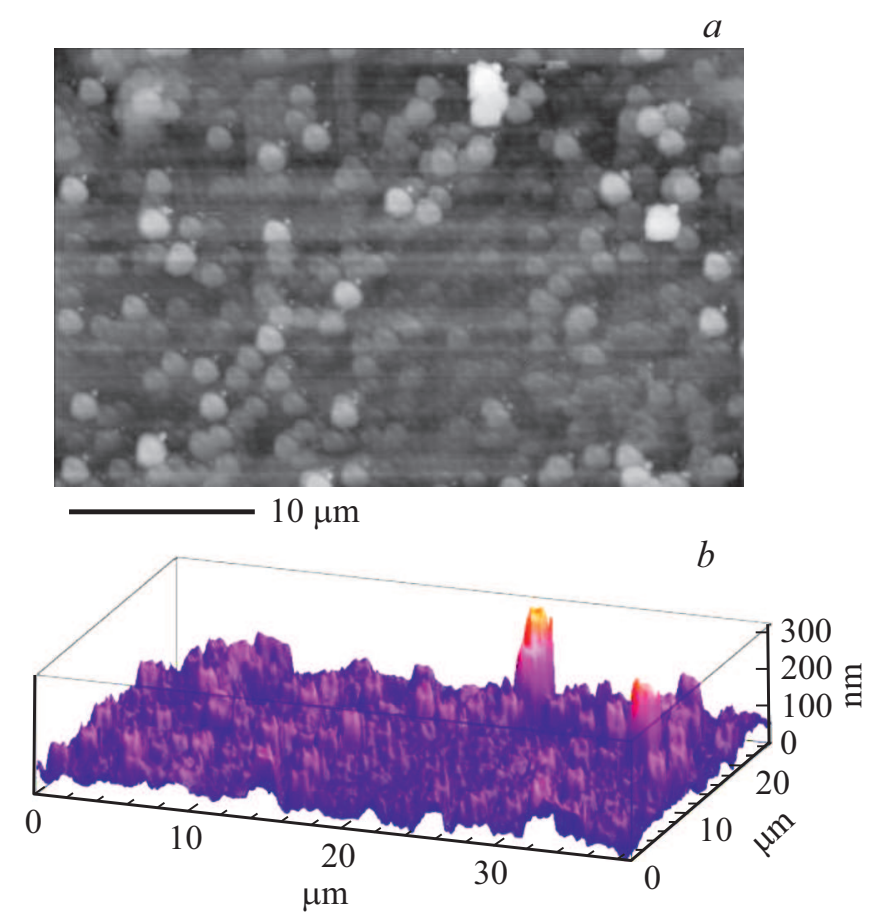

Рис. 4. Микрофотографии частиц супрамолекулярного комплекса ND-EuB в гель-пленке: 2D $(a)$ и 3D $(b)$ изображения. 


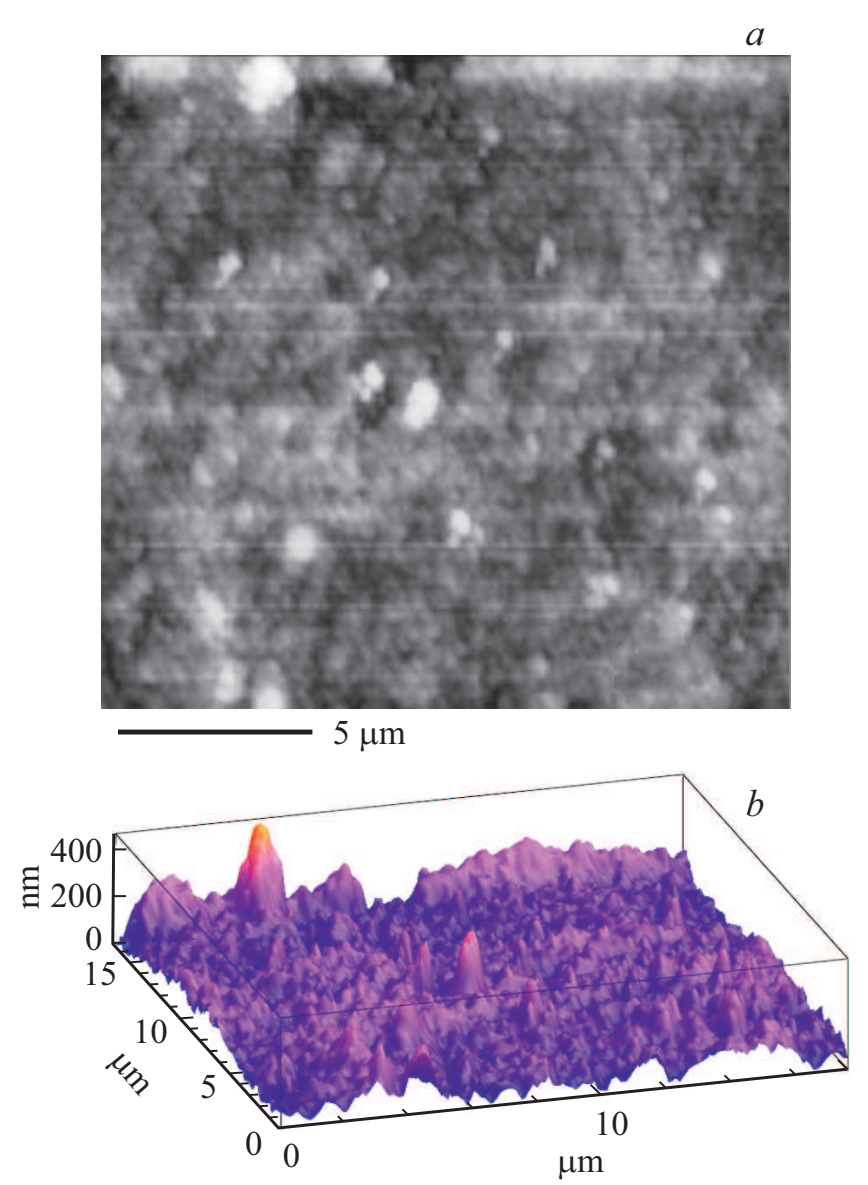

Рис. 5. Микрофотографии частиц супрамолекулярного комплекса ND-EuB в PAN-пленке: 2D $(a)$ и 3D $(b)$ изображения.

больших размеров (в среднем до $250 \mathrm{~nm}$ ) обусловлены агрегатами наночастиц.

В ряду матриц PS, PVB, PMMA, PAN и SOL-GEL величина пропускания $T$ в видимой области $(\lambda=500 \mathrm{~nm})$ приблизительно составила 57, 78, 81, 75 и $89 \%$ при толщине пленок соответственно около $70,60,60,50$ и $20 \mu \mathrm{m}$ и концентрации активатора $10^{-4} \mathrm{M}$, что свидетельствует о хорошем светопропускании полученных нами пленок.

Оценка фотостабильности пленок осуществлялась после облучения их светом ксеноновой лампы ДКсШ120 через фильтр ПС-11, имеющий две полосы пропускания: первую в УФ области, $220-420 \mathrm{~nm}$ и вторую в красной и ИК областях, $650-3000 \mathrm{~nm}$. После прохождения через фильтр измеренная величина уровня облученности образца составляла $\sim 0.4 \mathrm{~W} / \mathrm{cm}^{2}$. Время облучения $-1 \mathrm{~h}$. Фотостабильность образцов после облучения оценивалась по изменению СВЛ относительно исходных. Оказалось, что наименее фотостабильными показали себя пленки на основе PS и PMМА, наиболее фотостабильными - на основе гель-стекла. Например, после облучения интенсивность СВЛ пленок на основе PS и PMMA уменьшалась на $15-20 \%$, также происходило некоторое слабое размытие структуры спектров. Для гель-пленок наблюдалось слабое смещение СВЛ в коротковолновую область за счет падения интенсивности на длинноволновом склоне спектра (на 5-7\%) и примерно таком же возрастании ее на коротковолновом. Наблюдаемые изменения СВЛ свидетельствуют о сравнительно хорошей фотостабильности пленок, так как уровень облученности в УФ области был достаточно высоким: в диапазонах $220-300,300-350$ и $350-420 \mathrm{~nm}$ соответственно около 12,72 и $127 \mathrm{~mW} / \mathrm{cm}^{2}$.

\section{Заключение}

Проведено исследование свойств люминесцентных материалов в виде пленок, полученных путем введения в различные полимеры или гель-стекло супрамолекулярного алмазсодержащего комплекса европия (III) с батофенантролином. В этом комплексе структурообразующим элементом служили наноалмазы детонационного синтеза. В качестве матрицы-хозяина использовались такие полимеры как PS, PVB, PMMA, PAN и SOLGEL. Из представленных результатов видно, что полученные нами пленки являются эффективными преобразователями УФ излучения в диапазоне $220-410 \mathrm{~nm}$ в люминесценцию ионов европия $\mathrm{Eu}^{3+}$ на длине волны около $615 \mathrm{~nm}$. Об этом также свидетельствуют оценки квантовых выходов $\varphi$, значения которых в ряду PS, PVB, PMMA, PAN и SOL-GEL составляют 0.58, 0.46, 0.37, 0.30 и 0.78. При этом четко прослеживается влияние матрицы (вида полимера) на положение и форму полос возбуждения. Наибольшей шириной полосы возбуждения характеризуется пленка на основе PAN. Полуширина главной полосы излучения (переход ${ }^{5} D_{0}-{ }^{7} F_{2}$ ) также зависит от вида матрицы и в том же ряду матриц составляет $3.5,3.5,3.5,9.0$ и $17.0 \mathrm{~nm}$. С учетом того, что состав пленок можно варьировать, можно утверждать о возможности регулирования степени монохроматичности света в области $615 \mathrm{~nm}$. Очевидно, что с повышением полуширины полосы $615 \mathrm{~nm}$ возрастает и относительный вклад излучения на этой длине волны в полный спектр излучения ионов $\mathrm{Eu}^{3+}$. Таким образом, подбор типа полимера для синтезированных нами материалов открывает возможность управления формой полос поглощения и излучения в заданном спектральном диапазоне.

В целом микрофотографии, полученные на сканирующем зондовом микроскопе, свидетельствуют о возможности получения пленок с достаточно высокой однородностью, что обусловлено морфологией частиц полученного комплекса и высокой степенью его диспергирования в матричном материале. Известно, что диспергирование алмазсодержащего комплекса в обьеме матрицы безусловно приводит к усилению механической прочности пленок (с учетом свойств ND-частиц). Присутствие ND-частиц также увеличивает адгезию пленок к поверхности за счет взаимодействий между частицами ND и поверхностью.

По совокупности свойств исследованных материалов можно утверждать, что все они могут найти свою нишу 
для использования в зависимости от конкретных областей возможного применения. Наиболее перспективной, на наш взгляд, является матрица на основе гель-стекла.

\section{Конфликт интересов}

Авторы заявляют, что у них нет конфликта интересов.

\section{Список литературы}

[1] Binnemans $K$. Handbook on the Physics and Chemistry of Rare Earths / Ed. by Gschneidner K.A., Jr., Bünzli J.-C.G., Pecharsky V.K. Amsterdam: Elsevier, 2005. P. 107-272.

[2] Юрре Т.А., Рудая Л.И., Климова Н.В., Шаманин В.В. // ФТП. 2003. Т. 37. № 7. С. 835.

[3] Fukuda T., Kato S., Kin E., Okaniwa K., Morikawa H., Honda Z., Kamata N. // Opt. Mater. 2009. V. 32. P. 22-25.

[4] Binnemans $K$. Handbook on the Physics and Chemistry of Rare Earths / Ed. by Bünzli J.-C.G., Pecharsky V.K. Newnes, 2013. V. 44. P. $169-282$.

[5] Gavriluta A., Fix T., Nonat A., Slaoui A., Guillemoles J.F., L.J. // J. Mater. Chem. A, 2017. V 5. P. 14031-14040.

[6] Kido J., Okamoto Y. // Chem. Rev. 2002. V. 102. N 6. P. 2357.

[7] Sun P.P., Duan J.P., Lih J.J., Cheng C.H. // Adv. Func. Mater. 2003. V. 13. N 9. P. 683.

[8] Pereira A., Conte G., Gallardo H., Zucco C.,Quirino W., Legnani C., Cremona M., Bechtold I. // J. of the Soc. for Inform. Display. 2011. V. 19. N 11. P. 793.

[9] Zhao B., Zhang H., Miao Y., Wang Z., Gao L., Wang H., Hao Y., Xu B., Li W. // J. Mater. Chem. C, 2017. Iss. 46. P. 12182.

[10] Hadjichristov G.B., Stefanov I.L., Stanimirov S.S., Petkov I.K. // Proc. of SPIE - The International Society for Optical Engineering. $7501: 23.2009$.

[11] Mitsuishi M., Kikuchi Sh., Miyashita T., Amao Y. // J. Mater. Chem. 2003. V. 13. P. 2875.

[12] Brites C.D.S., Lima P.P., Silva N.J.O., Millán A., Amaral V.S., Palacio F., Carlos L.D. // Adv. Mater. 2010. V. 22. P. 44994504.

[13] Kozak M., Kalota B., Tkaczyk S., Tsvirko M. // Журн. прикл. спектр. 2014. T. 81. N 4. C. 622.

[14] Gameiro C.G., da Silva Jr.E.F., Alves S., de Sá G.F., SantaCruz P.A. // Mat. Sci. Forum. 1999. V. 315-317. P. 249.

[15] Аксенова Н.А., Глаголев Н.Н., Шашкова В.Т., Зайченко Н.Л., Кольцова Л.С., Мардалейшвили И.Р., Шиенок А.И., Тимашев П.С., Западинский Б.И., Соловьева А.Б. // ЖФХ. 2008. Т. 82. № 9. С. 1759.

[16] Moudam O., Rowan B.C., Alamiry M., Richardson P., Richards B.S., Jones A.C., Robertson N. // Chem. Commun. 2009. V. 43. P. 6649.

[17] Knyazev A.A., Karyakin M.E., Krupin A.S., Romanova K.A., Galyametdinov Yu.G. // Eur. J. Inorg. Chem. 2017. P. 639-645.

[18] Лапаев Д.В., Князев А.А., Галяметдинов Ю.Г. Никифоров В.Г., Джабаров В.И., Лобков В.С. // Вестн. технологич. университета. 2017. Т. 20. № 18. С. 26.

[19] Lunstroot K., Driesen K., Nockemann P., GörllerWalrand C., Binnemans K., Bellayer S., Le Bideau J., Vioux A. // Chem. Mater. 2006. V. 18 (24). P. 5711-5715.

[20] Levchenko V., Reisfeld R. // Opt. Mater. 2017. V. 74. N 12. P. 187190 .
[21] Киреев С.В., Иванов Р.А., Формановский А.А., Егоров А.А., Кузьмина Н.П. // Журн. неорг. химии. 2003. Т. 48. № 6. C. 903.

[22] Azab H.A., Al-Deyab S.S., Anwar Z.M., Ahmed R.Gh. // J. Chem. Eng. Data. 2011. V. 56. P. 833.

[23] Бочков М.А., Витухновский А.Г., Тайдаков И.В., Ващенко А.А., Кацаба А.В., Амброзевич С.А., Брунков П.Н. // ФТП. 2014. Т. 48. № 3. С. 384.

[24] Лапина В.А., Павич Т.А., Першукевич П.П. // ОПт. и спектр. 2017. Т. 122. № 2. C. 241-251. 